\title{
Editorial: Community Informatics in Brazil
}

\author{
Michael Gurtein, PhD. \\ Editor in Chief, The Journal of Community Informatics \\ gurstein@gmail.com
}

I am delighted and honoured to publish this special double issue on The Internet and Community Informatics in Brazil. The issue itself is a very strong one and I think it both represents and solidifies the very strong Community Informatics range of activities and traditions in Brazil while pointing to certain characteristics of Community Informatics in Brazil that are potentially of interest and importance for the rest of the world.

The special issue editors, Suely Fragoso and Gilda Olinto in their introduction to the issue have provided a very useful introduction to the range of issues that are of interest from a broad $\mathrm{Cl}$ perspective but there are a few other items which an outsider might identify which someone closer to the scene such as they might overlook.

A first observation and this comes out very strongly in the Fragoso and Olinto overview as well as a number of the papers is the strong recognition in Brazil of the social determinants of Internet use, and the need by government through policy and programmes to respond to this so as to not have the Internet exacerbate already significant social and economic divisions. As a Less Developed Country rapidly moving to becoming a middle income country, a regional power, and a member of a global group of similar regional middle income powers Brazil very well recognizes the drag that significant digital inequality can present to its aspirations for development and equally the opportunities that are available as these inequalities are being addressed.

There is a clear recognition on the part of the national and even state governments in Brazil that responding to digital inequality is a responsibility of the State and the result has been the assignment of considerable public resources to responding including through the range of programs and initiatives that Suely and Gilda and others have noted in their papers. From the papers in this issue it is clear that the governments of Brazil are making extraordinary efforts to broaden the base of Internet access and use. In addition, again from the information presented in this issue the efforts towards digital inclusion are being done with a considerable measure of creativity and imagination reflecting in considerable degree Brazil's unique multi-ethnic and multi-cultural heritage and building on this through linking Internet access and use to cultural production particularly in music but also in graphics and the visual arts.

Regrettably most of these initiatives are little known outside of Brazil or beyond Latin America or others in the Portuguese speaking world and it is one intention of this special issue to help in a small way to overcome these gaps. 
One additional observation comes from a closer reading of the articles in this issue and that is the close connections between the digital inclusion efforts and programmes and Brazil's long and effective experience with community based processes and particularly community based education. Brazil has contributed a very great deal to the practice but especially and notably the theory of community based initiatives and community development overall and it is of special interest and with some excitement that I note that this issue is making a very strong set of conceptual and theoretical connections between this tradition - most notably through the work of the Brazilian educator Paulo Freire.

For me this was an unexpected discovery and I have been particularly delighted to see the ways in which this community-based approach to education and especially literacy education is being applied to processes of digital inclusion in various regions of Brazil and with various of the more marginalized populations. As well, and of particular note is the way in which the theorizing in this area of the observed processes and emergent formations of community development fits so directly into my understanding of an emerging community informatics theory while deepening and extending these somewhat tentative and still partial developments.

Community Informatics for many is a linking of the processes of community development with the content, affordances and historical and technological dynamics of Information and Communications Technologies. In the English speaking context, and particularly through work coming from Information Sciences and Science and Technology Studies there has been considerable advance in understanding and to a degree in conceptualizing the processes of technology change and the ways in which technology and particularly the Internet provides opportunities to communities and individuals for advancement and change. We now know quite a lot about networking, about management at a distance, about identity in a digital environment - to point to only a few. However, from a $\mathrm{Cl}$ perspective there has been much less theorizing and a much shallower pool of conceptualization to draw upon when one is looking at the community development side of the $\mathrm{Cl}$ equation. What are the processes and dynamics which can be enabled at the community level which in turn can result in the absorption and effective utilization of ICTs.

The links to the work conceptualizing community development and community processes in Brazil goes some way, I believe towards providing a deepening of understanding of the dynamics of communities and through certain of the articles in this special issue we begin to see examples in practice of how these conceptualizations can inform $\mathrm{Cl}$ practice as well. While only two of the articles in this issue (Alvear et al and Maia et al) point specifically to Freire as influences, several of the other articles clearly are linked into a similar set of concerns - linking technology to processes of community enablement, recognizing community enablement and technology training and development as a process of coming into a position of self recognition and understanding, linking education into processes of the creation of a self-understanding of 
economic and social contexts, and overall a strong sense that in community development including for technology skills and understanding can be most effective when understood as an emergent process of communities and individuals coming into self-awareness. In this external formal community supports have to be seen and introduced simply as tools and enablers of these processes but as not the fundamental structures by means of which these processes occur.

This linking of community process, emergent self-awareness, self and community empowerment, with ICTs particularly for marginalized populations is at the very core of a community informatics and thus this issue and the practice of community informatics in Brazil has much to teach all of those with an interest in or activities to support Community Informatics anywhere in the world. 